\title{
Recombinant FVIII Products (Turoctocog Alfa and Turoctocog Alfa Pegol) Stable Up to $40^{\circ} \mathrm{C}$
}

This article was published in the following Dove Press journal:

Journal of Blood Medicine

\author{
Mariasanta Napolitano (D) \\ Arne Agerlin Olsen ${ }^{2}$ \\ Anne Mette $\mathrm{N} \varnothing \mathrm{hr}\left(\mathbb{D}^{2}\right.$ \\ Hermann Eichler ${ }^{3}$ \\ 'Department of Health Promotion, Mother \\ and Child Care, Internal Medicine and \\ Medical Specialties (PROMISE), University \\ of Palermo Reference Regional Center for \\ Thrombosis and Hemostasis, Hematology \\ Unit, Palermo, Italy; ${ }^{2}$ Novo Nordisk A/S, \\ Biopharm Manufacturing Development, \\ Gentofte, Denmark; ${ }^{3}$ Saarland University \\ and Saarland University Hospital, Institute \\ of Clinical Haemostaseology and \\ Transfusion Medicine, Homburg (Saar), \\ Germany
}

Purpose: The stability under high-temperature conditions of factor VIII (FVIII) concentrates for replacement therapy is of critical importance to patients, particularly those who reside in, or travel to, regions with high ambient temperatures. Concerns about product stability may limit or prevent access to treatment for patients and may limit their ability to live a close-to-normal life. This study evaluated the effect of hot and humid storage conditions on the long-term stability of the recombinant FVIII products, turoctocog alfa and turoctocog alfa pegol.

Methods: Turoctocog alfa samples were assessed for stability at $30^{\circ} \mathrm{C}$ for 9 months or $40^{\circ} \mathrm{C}$ for 3 months following storage at $5^{\circ} \mathrm{C}$ for 21 or 27 months, respectively, while turoctocog alfa pegol samples were assessed at $30^{\circ} \mathrm{C}$ for 12 months or $40^{\circ} \mathrm{C}$ for 3 months following storage at $5^{\circ} \mathrm{C}$ for 18 or 27 months, respectively. In addition, turoctocog alfa and turoctocog alfa pegol dry powders were evaluated for stability at $5^{\circ} \mathrm{C} /$ ambient humidity (AH) for 30 months, $30^{\circ} \mathrm{C} / 75 \%$ relative humidity $(\mathrm{RH})$ for 12 months and $40^{\circ} \mathrm{C} / 75 \% \mathrm{RH}$ for 6 months. Both studies utilized a range of product strengths. Key stability assessments included oxidized forms, potency, water content and high molecular weight protein (HMWP).

Results: Both turoctocog alfa and turoctocog alfa pegol remained stable following storage at $40^{\circ} \mathrm{C} / 75 \% \mathrm{RH}$ for 3 months, and at single temperatures $\left(5^{\circ} \mathrm{C} / \mathrm{AH}, 30\right.$ and $\left.40^{\circ} \mathrm{C} / 75 \% \mathrm{RH}\right)$, without any major increase in HMWP or any impairment of potency or water content.

Conclusion: Turoctocog alfa and turoctocog alfa pegol offer stability at $40^{\circ} \mathrm{C}$ for up to 3 months without jeopardizing the quality of each product. These stability characteristics may offer patients flexibility with product storage and daily use.

Keywords: factor VIII, hemophilia A, storage flexibility, temperature stability, turoctocog alfa, turoctocog alfa pegol

\section{Plain Language Summary}

For patients with hemophilia A and their caregivers, it is crucial that factor VIII (FVIII) products used for replacement therapy can be stored under intense heat for long time periods. Concerns about whether their FVIII products are affected by intense heat may prevent patients from accessing treatment and living a normal life when they are in hot and humid regions. This study therefore evaluated the effect of temperatures up to $40^{\circ} \mathrm{C}$ and humid storage conditions on the long-term stability of the FVIII products: turoctocog alfa and turoctocog alfa pegol.

Turoctocog alfa samples were assessed for stability at $30^{\circ} \mathrm{C}$ for 9 months or $40^{\circ} \mathrm{C}$ for 3 months following storage at $5^{\circ} \mathrm{C}$ for 21 or 27 months, respectively, while turoctocog alfa pegol samples were assessed at $30^{\circ} \mathrm{C}$ for 12 months or $40^{\circ} \mathrm{C}$ for 3 months following storage at $5^{\circ} \mathrm{C}$ for 18 or 27 months, respectively. In addition, turoctocog alfa and turoctocog alfa pegol were evaluated for stability at $5^{\circ} \mathrm{C} /$ ambient humidity (AH) for 30 months, $30^{\circ} \mathrm{C} / 75 \%$ relative humidity $(\mathrm{RH})$ for 12 months and $40^{\circ} \mathrm{C} / 75 \% \mathrm{RH}$ for 6 months.
Correspondence: Anne Mette Nøhr Biopharm Manufacturing Development, Novo Nordisk A/S, Nybrovej 80,

Gentofte 2820, Denmark

Tel +4530751619

Email amnq@novonordisk.com

Journal of Blood Medicine 2021:12 9-20 
We found both FVIII products remained stable following storage at $40^{\circ} \mathrm{C} / 75 \% \mathrm{RH}$ for 3 months, and at single temperatures $\left(5^{\circ} \mathrm{C} / \mathrm{AH}, 30\right.$ and $\left.40^{\circ} \mathrm{C} / 75 \% \mathrm{RH}\right)$, without any major increase in protein products or impairment of potency or water content.

Turoctocog alfa and turoctocog alfa pegol offer stability at $40^{\circ} \mathrm{C}$ for up to 3 months without jeopardizing the quality of each product. These stability characteristics offer patients flexibility with product storage and daily use.

\section{Introduction}

In patients with hemophilia $\mathrm{A}$, it is recommended to treat bleeds with factor VIII (FVIII) within 2 hours, ${ }^{1,2}$ which requires access to replacement factor at all times. Furthermore, FVIII prophylaxis - the gold standard of care for severe hemophilia A patients-requires patients or their caregivers to administer regular intravenous injections of FVIII (usually every other day or 3 times a week with standard half-life FVIII concentrates ${ }^{2}$ and once or twice weekly with extended half-life [EHL] FVIII products). ${ }^{3}$

Manufacturers recommend storing both standard and EHL FVIII products in a refrigerator (or below $25^{\circ} \mathrm{C}$ ) and reconstituting them at room temperature. However, some patients are unaware that most FVIII products remain stable for a limited time at higher temperatures; ${ }^{4-15}$ therefore, their adherence to (and satisfaction with) therapy may be adversely affected by the perceived limitations of FVIII product storage conditions, particularly when patients are traveling. ${ }^{15-17}$ With reference to productrelated factors for hemophilia treatment, patients have reported a preference for storage-flexible products that allow reduced injection times, greater patient adherence, less waste, greater ease of handling, and fewer restrictions in daily activities such as travel and sports. ${ }^{15}$

The structural stability of recombinant therapeutic products can affect biological activity, clearance, and immunogenicity, with increasing instability occurring over long-term storage. ${ }^{18}$ While the World Health Organization recommendations are that the stability of therapeutic products should be assessed based on climatic zones with a maximum temperature of $30^{\circ} \mathrm{C}$ and $75 \%$ relative humidity (RH; Figure 1), they also recognize that storage conditions often exceed these temperatures. ${ }^{19}$ It is thus crucial to also assess the stability of FVIII products at temperatures above $30^{\circ} \mathrm{C}$.

Turoctocog alfa $\left(\right.$ NovoEight $^{\circledR}$, Novo Nordisk A/S, Bagsværd, Denmark) and turoctocog alfa pegol (an extended half-life glycoPEGylation of turoctocog alfa, Esperoct ${ }^{\circledR}$, Novo Nordisk A/S, Bagsværd, Denmark) are recombinant FVIII (rFVIII) products developed to prevent and treat bleeding

Figure I ICH quality guidelines for pharmaceutical stability storage. (https://qI scientific.com/ich-quality-guidelines/)

Notes: Long-term testing conditions for: Zone I, $21^{\circ} \mathrm{C} / 45 \% \mathrm{RH}$ (temperate); Zone II, $25^{\circ} \mathrm{C} / 60 \% \mathrm{RH}$ (subtropical and Mediterranean); Zone III, $30^{\circ} \mathrm{C} / 35 \% \mathrm{RH}$ (hot $/ \mathrm{dry}$ ); Zone IV, $30^{\circ} \mathrm{C} / 75 \% \mathrm{RH}$ (hot/very humid). Data from WHO. ${ }^{19}$

Abbreviations: $\mathrm{ICH}$, International Council on Harmonisation; RH, relative humidity; WHO, World Health Organization. 
episodes in patients with hemophilia $\mathrm{A}^{20-26}$ The activated forms of both products have the same primary structure as native activated FVIII. ${ }^{27}$ The production steps for turoctocog alfa are the same as for turoctocog alfa pegol prior to PEGylation; ${ }^{27-29}$ importantly, PEGylation of turoctocog alfa does not affect product stability. ${ }^{27}$ Both products are supplied as a dry powder in single-dose vials of 250, 500, 1000, 1500, 2000, and $3000 \mathrm{IU}$ (turoctocog alfa) ${ }^{7,8}$ and 500, 1000, 1500, 2000, and $3000 \mathrm{IU}$ (turoctocog alfa pegol). ${ }^{13,14}$ The current approved storage and shelf life of the dry powder for both products is storage at $5^{\circ} \mathrm{C}$ for up to 30 months, during which time the products may be stored at room temperature $\left(\leq 30^{\circ} \mathrm{C}\right)$ for $\leq 12$ months or up to $40^{\circ} \mathrm{C}$ for $\leq 3$ months. ${ }^{7,8,13,14}$

Patients may live in, or travel to, countries with a hot and humid climate. To allow these patients to use turoctocog alfa and turoctocog alfa pegol safely, we evaluated the effect of high-temperature, high-humidity storage conditions on the long-term stability of both products. In the first study, turoctocog alfa samples were assessed at $30^{\circ} \mathrm{C}$ for 9 months or $40^{\circ} \mathrm{C}$ for 3 months following storage at $5^{\circ} \mathrm{C}$ for 21 or 27 months, respectively, while turoctocog alfa pegol samples were assessed at $30^{\circ} \mathrm{C}$ for 12 months or $40^{\circ} \mathrm{C}$ for 3 months following storage at $5^{\circ} \mathrm{C}$ for 18 or 27 months, respectively. The second study assessed the dry powders of turoctocog alfa and turoctocog alfa pegol when stored at $5^{\circ} \mathrm{C} /$ ambient humidity (AH) for 30 months, $30^{\circ} \mathrm{C} / 75 \% \mathrm{RH}$ for 12 months, and $40^{\circ} \mathrm{C} / 75 \%$ RH for 6 months (Figure 2).

\section{Patients and Methods Product and Sample Preparation}

Commercially available turoctocog alfa and turoctocog alfa pegol in dry-powder batches were each evaluated at their lowest and two highest strengths: 250, 2000, and $3000 \mathrm{IU}$ for turoctocog alfa, and 500, 2000, and $3000 \mathrm{IU}$ for turoctocog alfa pegol (Figure 2).

\section{Long-Term Stability Study Turoctocog Alfa}

The long-term stability of turoctocog alfa dry-powder batches was assessed during single temperature storage at $40^{\circ} \mathrm{C}\left( \pm 2^{\circ} \mathrm{C}\right)$ and $75 \% \mathrm{RH}( \pm 5 \% \mathrm{RH})$ for 3 months, and at $30^{\circ} \mathrm{C}\left( \pm 2^{\circ} \mathrm{C}\right)$ and $75 \% \mathrm{RH}( \pm 5 \% \mathrm{RH})$ for 9 months. A reference sample for each dose was maintained at $5^{\circ} \mathrm{C}$ $\left( \pm 3^{\circ} \mathrm{C}\right)$ in darkness and $\mathrm{AH}$ for 3 months. Prior to the start of this study, the turoctocog alfa samples had been stored at $5^{\circ} \mathrm{C}$ $\left( \pm 3^{\circ} \mathrm{C}\right)$ in darkness and $\mathrm{AH}$ for 21 and 27 months (Figure 2).

\section{Turoctocog Alfa Pegol}

Dry-powder batches of turoctocog alfa pegol were assessed for long-term stability at $40^{\circ} \mathrm{C}\left( \pm 2^{\circ} \mathrm{C}\right)$ in darkness and $75 \% \mathrm{RH}( \pm 5 \% \mathrm{RH})$ for 3 months, and at $30^{\circ} \mathrm{C}\left( \pm 2^{\circ} \mathrm{C}\right)$ and $75 \% \mathrm{RH}( \pm 5 \% \mathrm{RH})$ for 12 months. Prior to the start of this study, the dry products had been stored at $5^{\circ} \mathrm{C}\left( \pm 2^{\circ} \mathrm{C}\right)$ in darkness and $\mathrm{AH}$ for 18 and 27 months for consecutive temperature storage (Figure 2).

\section{Stability Assessments and Assay Methods}

All studies were performed according to current International Conference on Harmonisation (ICH) bracketing design guidelines. ${ }^{30}$ The key stability parameters assessed for both products were those from the drug product specifications that are susceptible to change during storage and/or those that could potentially influence product quality: namely, oxidized forms, potency, water content, and high-molecular-weight protein (HMWP). For

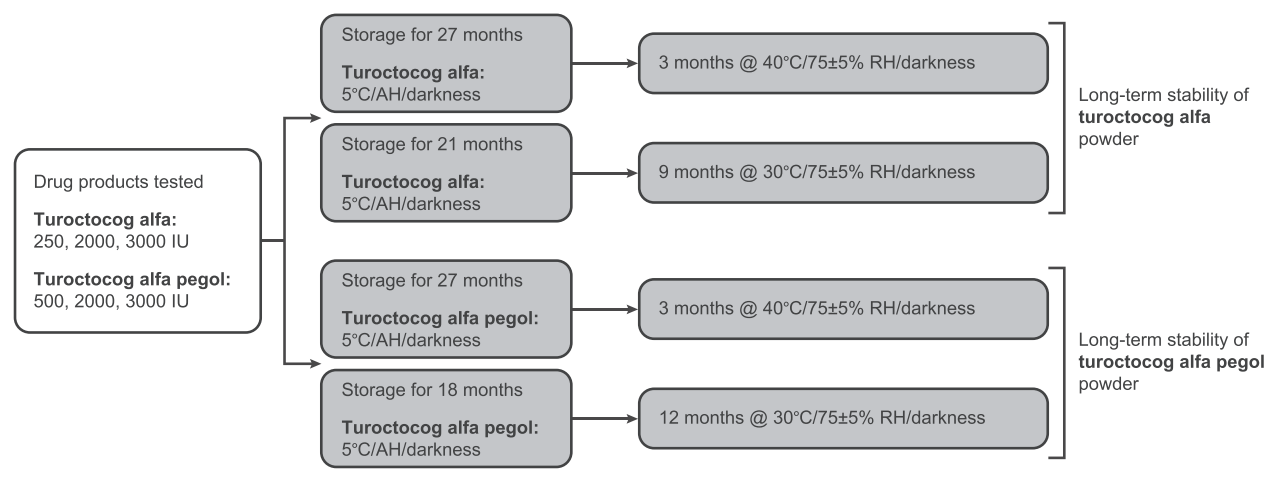

Figure 2 Study design.

Notes: The stability of turoctocog alfa dry powder product was assessed after storage at $5^{\circ} \mathrm{C}$ for 27 months followed by $40^{\circ} \mathrm{C}$ for 3 months (reference samples maintained at $5^{\circ} \mathrm{C}$ for 3 months) and after storage at $30^{\circ} \mathrm{C}$ for 9 months following storage at $5^{\circ} \mathrm{C}$ for 21 months. The stability of turoctocog alfa pegol dry powder product was also assessed after storage at $5^{\circ} \mathrm{C}$ for 27 months, followed by $40^{\circ} \mathrm{C}$ for 3 months and after storage at $30^{\circ} \mathrm{C}$ for 12 months following storage at $5^{\circ} \mathrm{C}$ for 18 months. Abbreviations: $\mathrm{AH}$, ambient humidity; IU, international units; $\mathrm{RH}$, relative humidity. 
oxidized forms, potency, water content, and HMWP, the results from all assays were evaluated against predetermined acceptance limits and calculated using appropriate statistical methods. ${ }^{30}$ Potency was expressed as $\%$ target. The specific ranges for each assay are noted within the appropriate sections below.

\section{Oxidized Forms}

Oxidized forms within the reconstituted turoctocog alfa and turoctocog alfa pegol products were assessed using reverse-phase-high performance liquid chromatography (RP-HPLC). Analysis was performed on an HPLC system equipped with processing software and a 4.0 × $250-\mathrm{mm}$, $\mathrm{C}_{4} 5 \mu \mathrm{m}, 300 \AA$ column (Novo Nordisk Pharmatech A/S, Køge, Denmark). The column temperature was set at $40^{\circ} \mathrm{C}$ for turoctocog alfa and $40^{\circ} \mathrm{C} \pm 2{ }^{\circ} \mathrm{C}$ for turoctocog alfa pegol, with a detection wavelength of $215 \mathrm{~nm}$. A gradient of $35-100 \%$ eluent B $(0.09 \%$ [turoctocog alfa] or $0.14 \%$ [turoctocog alfa pegol] trifluoroacetic acid [TFA] in $80 \%$ acetonitrile in purified water) and $65-0 \%$ eluent $\mathrm{A}(0.1 \%$ [turoctocog alfa] or $0.15 \%$ [turoctocog alfa pegol] TFA in purified water) was applied over a 40-min period with a flow rate of $1 \mathrm{~mL} / \mathrm{min}$. The composition of $100 \%$ eluent $\mathrm{B}$ was then maintained for $5 \mathrm{~min}$, before being changed back to the initial conditions over $1 \mathrm{~min}$, followed by column equilibration for $14 \mathrm{~min}$, resulting in a total run time of $60 \mathrm{~min}$. Oxidized forms were calculated as the percentage area on the resulting chromatograms. RPHPLC chromatograms showed all components were present in the drug substances and therefore in the drug products (chromatograms not shown).

\section{Potency}

The potency of turoctocog alfa and turoctocog alfa pegol was investigated using the chromogenic assay (Chromogenix Coamatic ${ }^{\circledR}$ Factor VIII) and the SynthASil (HemosIL, Instrumentation Laboratory) activated partial thromboplastin time reagent. ${ }^{27}$

Turoctocog alfa and turoctocog alfa pegol product samples, calibrator, and blank samples were analyzed in triplicate on the $\mathrm{ACL}^{\circledR}$ Elite Pro analyzer. Absorbance readings for product, reference samples, and calibrator were used to calculate potency using slope-ratio analysis or parallel line regression (chromogenic assays). Potency was expressed as \% target (European Pharmacopoeia acceptance limits are $80-125 \%$ of target). ${ }^{31}$

\section{Water Content}

The water content of turoctocog alfa and turoctocog alfa pegol samples was evaluated using near-infrared (NIR) spectroscopy for the high-temperature stability samples only. NIR spectroscopy was conducted using a Fourier transform-NIR Spectrometer (MPA, Bruker, Billerica, MA, USA) equipped with an integrating sphere (or equivalent). Both products were scanned in the frequency ranges of 7502.1-6098.1 and 5450.1-4597.7 $\mathrm{nm}$ at a resolution of $8 \mathrm{~cm}^{-1}$, with an average of 32 scans being recorded for each spectrum. The spectrometer was equipped with OPUS software (Bruker) (or equivalent) and data were analyzed using a partial least squares fit method. Turoctocog alfa and turoctocog alfa pegol samples were analyzed without any pretreatment; however, NIR spectroscopy data were pretreated using vector normalization and a first derivative to enhance spectral information and correct interferences from the analyzed material that might otherwise induce baseline drift and changes in maximum absorbance. ${ }^{32}$ Karl-Fischer coulometry was used as the reference method for determining the calibration function and to analyze samples in cases where NIR results were not accepted (for example, due to persistent outliers). ${ }^{31}$

\section{High Molecular Weight Protein}

Size exclusion-HPLC (SE-HPLC) was used to determine the presence of protein aggregates in the turoctocog alfa and turoctocog alfa pegol samples. Prior to SE-HPLC analysis, the samples were reconstituted in either $1.0 \mathrm{~mL}(250-\mathrm{IU}$ samples [turoctocog alfa] and 500-IU samples [turoctocog alfa pegol]) or $4.3 \mathrm{~mL}$ (2000- and 3000-IU samples, both products) of $0.9 \%$ sodium chloride solution. SE-HPLC measurements for turoctocog alfa were performed using an HPLC system equipped with a Shodex PROTEIN KW-803, $8 \times 300$-mm column (Shodex), or equivalent. For turoctocog alfa pegol, SE-HPLC measurements were performed using a Sepax Technologies SRT SEC-500, $7.8 \times 300-\mathrm{mm}, 5-\mu \mathrm{m}$, $500 \AA$ Å column (Sepax Technologies, Newark, DE, USA). An elution flow rate of $0.4 \mathrm{~mL} / \mathrm{min}$ was employed for turoctocog alfa, using a column temperature of $30^{\circ} \mathrm{C}$ and excitation and emission detection wavelengths of 285 and $335 \mathrm{~nm}$, respectively. For turoctocog alfa pegol, an elution flow rate of $0.3 \mathrm{~mL} / \mathrm{min}$ was used, with a column temperature of $23^{\circ} \mathrm{C}$, an excitation detection wavelength of $285 \mathrm{~nm}$, and an emission detection wavelength of $345 \mathrm{~nm}$. The eluent buffer consisted of 10-mM TRIS, 10-mM CaCl $2,300-\mathrm{mM} \mathrm{NaCl}$, 
and 5\% 2-propanol at pH 7.0 (turoctocog alfa) or 10-M BISTRIS propanol, $10-\mathrm{mM}$ calcium acetate hydrate, $0.5-\mathrm{M}$ sodium chloride, and $10 \%$ isopropanol at a $\mathrm{pH}$ adjusted to 6.8 with acetic acid (turoctocog alfa pegol). The injection load volume was within the validated range of the method $(0.95-7.8 \mu \mathrm{g})$. Run times for products reconstituted in 4.3 - and $1.0-\mathrm{mL} 0.9 \%$ sodium chloride solutions were $\geq 70$ and $\geq 80 \mathrm{~min}$, respectively, for turoctocog alfa, and $60 \mathrm{~min}$ for turoctocog alfa pegol. HMWP content was determined by calculating the area percentage of the HMWP peak on the resulting chromatogram.

\section{Results \\ Oxidized Forms}

Oxidized forms, which are inactive forms of rFVIII that can reduce potency, ${ }^{33}$ are the stability-limiting factor. Oxidized forms increased as a function of time and temperature following an Arrhenius correlation for both products (Figure 3A). Results for turoctocog alfa samples stored at consecutive temperatures of $30^{\circ} \mathrm{C} / 75 \% \mathrm{RH}$ for 9 months (Figure $3 \mathrm{~B}$ ) or $40^{\circ} \mathrm{C} / 75 \% \mathrm{RH}$ for 3 months (Figure $3 \mathrm{C}$ ), following storage at $5^{\circ} \mathrm{C}$ for 21 or 27 months, respectively, showed that levels of oxidized forms were within the predetermined acceptance limits for all batches. Similar results were seen for turoctocog alfa pegol samples stored at consecutive temperatures of $30^{\circ} \mathrm{C} / 75 \% \mathrm{RH}$ for 12 months (Figure $3 \mathrm{G}$ ) or $40^{\circ} \mathrm{C} / 75 \% \mathrm{RH}$ for 3 months (Figure $3 \mathrm{H}$ ), following storage at $5^{\circ} \mathrm{C}$ for 18 or 27 months, respectively. There was a small increase in the occurrence of oxidized forms of both turoctocog alfa and turoctocog alfa pegol following storage at single temperatures of $5^{\circ} \mathrm{C}$, $30^{\circ} \mathrm{C} / 75 \% \mathrm{RH}$, and $40^{\circ} \mathrm{C} / 75 \% \mathrm{RH}$ for 30,12 , and 6 months, respectively (Figure $3 \mathrm{D}-\mathrm{F}$ and Figure $3 \mathrm{I}-\mathrm{K}$, respectively). For both products, oxidized forms were close to $5 \%$ after storage at $30^{\circ} \mathrm{C} / 75 \% \mathrm{RH}$ for 12 months (Figures 3E and $\mathrm{J}$ ) and approaching 7\% after storage at $40^{\circ}$ $\mathrm{C} / 75 \% \mathrm{RH}$ for 6 months (Figures $3 \mathrm{~F}$ and $\mathrm{K}$ ).

\section{Potency}

As potency is used as the basis for dosage calculations and treatment strategies, ${ }^{34}$ it is important to determine whether potency is affected by hot and humid storage conditions. Changes in potency were within the limits for all turocto$\operatorname{cog}$ alfa batches when stored at consecutive temperature conditions for 9 months (Figure 4A) or 3 months (Figure 4B), respectively. Potency was also within the limits for all turoctocog alfa pegol batches when stored at consecutive temperature conditions for 12 months (Figure 4F) or 3 months (Figure 4G), respectively. These limits are also in line with the European Pharmacopoeia acceptance criteria of $-20 \%$ to $+125 \%$ from target. ${ }^{31}$ The results of the potency test of dry turoctocog alfa and turoctocog alfa pegol samples stored at single temperatures for 30, 12, and 6 months, respectively, are shown in Figure 4C$\mathrm{E}$ and Figure $4 \mathrm{H}-\mathrm{J}$, respectively. Potency was maintained within the limits for all turoctocog alfa and turoctocog alfa pegol sample strengths tested.

\section{Water Content}

Excessive water content can increase degradation and reduce the stability of a therapeutic product. ${ }^{35}$ When turoctocog alfa batches were stored at consecutive temperature conditions for 9 months (Figure 5A) or 3 months (Figure 5B), respectively, water content for all batches was within the range of $1-2 \%$, corresponding to the observed ranges in stability studies. Likewise, water content was also within this upper range for all turoctocog alfa pegol batches when stored at consecutive temperature conditions for 12 months (Figure 5F) or 3 months (Figure 5G), respectively. There was a small increase in the water content with increasing temperature for both turoctocog alfa and turoctocog alfa pegol samples following storage at single temperatures for 30, 12, and 6 months, respectively (Figure $5 \mathrm{C}-\mathrm{E}$ and Figure $5 \mathrm{H}-\mathrm{J}$, respectively). Water content was approximately $1 \%$ after storage at $30^{\circ} \mathrm{C} / 75 \% \mathrm{RH}$ for 12 months (Figure 5D and I) and $<2 \%$ after storage at $40^{\circ} \mathrm{C} / 75 \% \mathrm{RH}$ for 6 months (Figure 5E and J).

\section{High Molecular Weight Protein}

Protein product aggregates, including HMWP, are described as potent inducers of immune responses to therapeutic protein products. ${ }^{36}$ When turoctocog alfa batches were stored at consecutive temperature conditions for 9 months (Figure 6A) or 3 months (Figure 6B), respectively, HMWP for all batches was within the range of $2-4 \%$. Similarly, HMWP was also within this upper range for all turoctocog alfa pegol batches when stored at consecutive temperature conditions for 12 months (Figure 6F) or 3 months (Figure 6G), respectively. Small increases in HMWP were observed for both turoctocog alfa and turoctocog alfa pegol samples following storage at single temperatures for 30, 12, and 6 months, respectively (Figure 6C-E and Figure $6 \mathrm{H}-\mathrm{J}$, respectively); for both products, HMWP levels were $\leq 3 \%$ after storage at $30^{\circ} \mathrm{C}$ / 


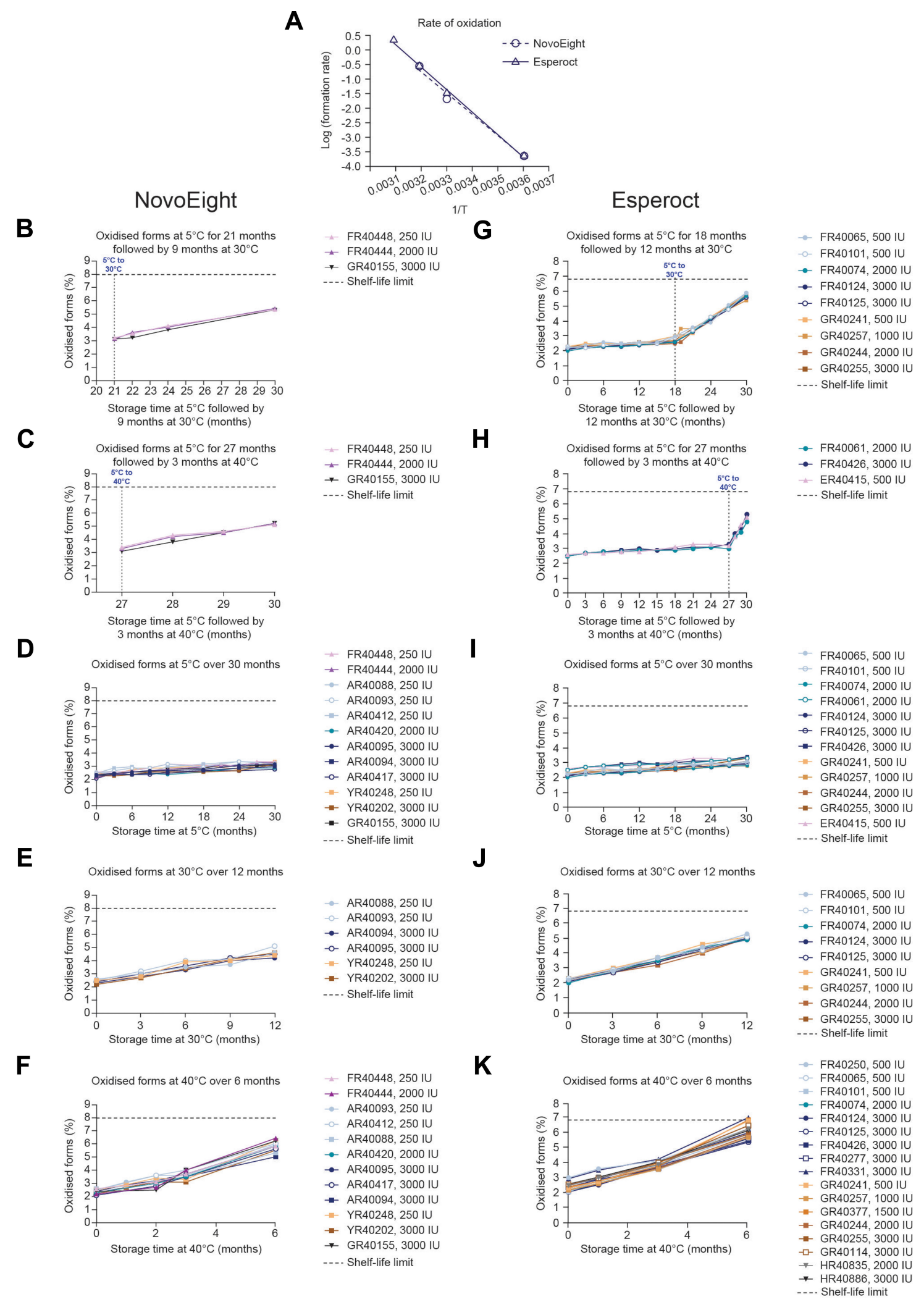

Figure 3 Oxidized forms of turoctocog alfa dry powder samples as the rate of oxidation (Arrhenius correlation) (A), when stored at $5^{\circ} \mathrm{C}$ for 21 months followed by storage at $30^{\circ} \mathrm{C}$ for 9 months (B), $5^{\circ} \mathrm{C}$ for 27 months followed by storage at $40^{\circ} \mathrm{C}$ for 3 months (C), and when stored at $5^{\circ} \mathrm{C}$ for 30 months (D), $30^{\circ} \mathrm{C}$ for 12 months (E), and $40^{\circ} \mathrm{C}$ for 6 months $(\mathbf{F})$. Oxidized forms of turoctocog alfa pegol dry powder samples when stored at $5^{\circ} \mathrm{C}$ for 18 months followed by storage at $30^{\circ} \mathrm{C}$ for 12 months $(\mathbf{G})$, $5^{\circ} \mathrm{C}$ for 27 months followed by storage at $40^{\circ} \mathrm{C}$ for 3 months $(\mathbf{H})$, and when stored at $5^{\circ} \mathrm{C}$ for 30 months $(\mathbf{I}), 30^{\circ} \mathrm{C}$ for 12 months $(\mathrm{J})$, and $40^{\circ} \mathrm{C}$ for 6 months $(\mathbf{K})$. Shelf-life limits for both products are shown by the horizontal dotted lines.

Abbreviations: IU, international units; T, temperature (in degrees Kelvin). 


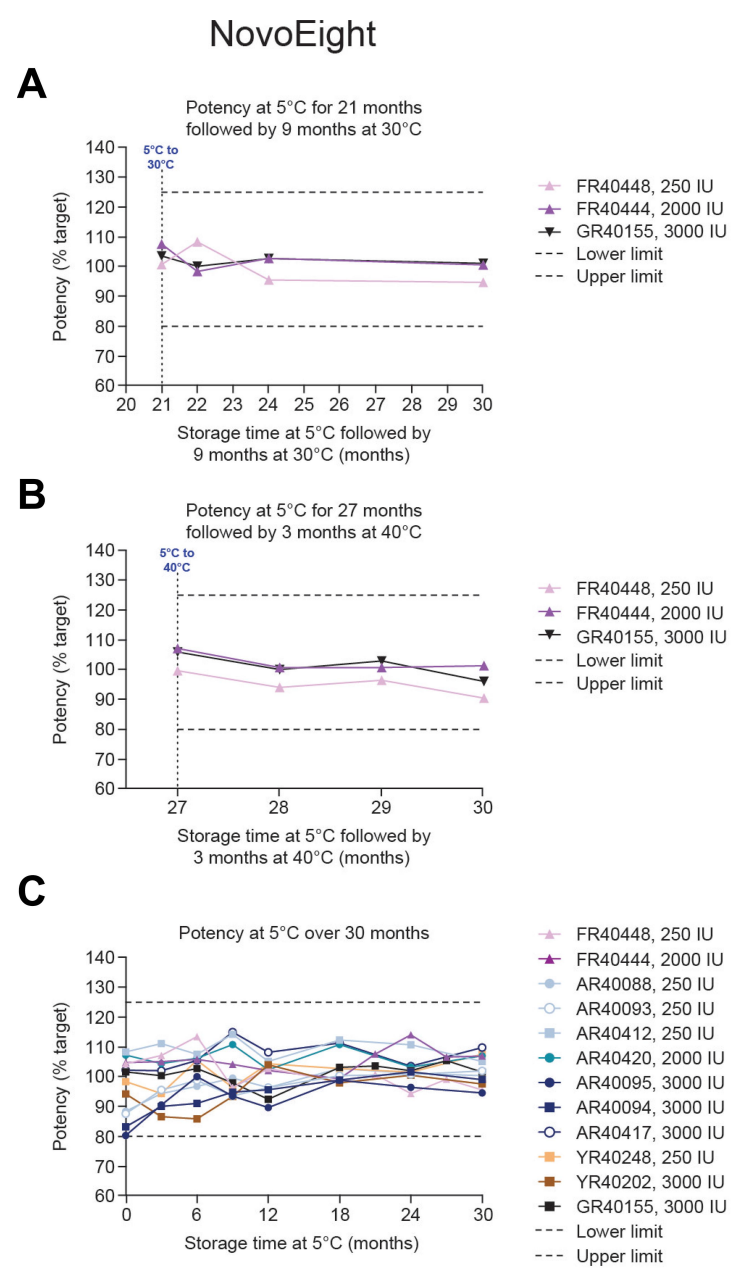

\section{Esperoct}

F

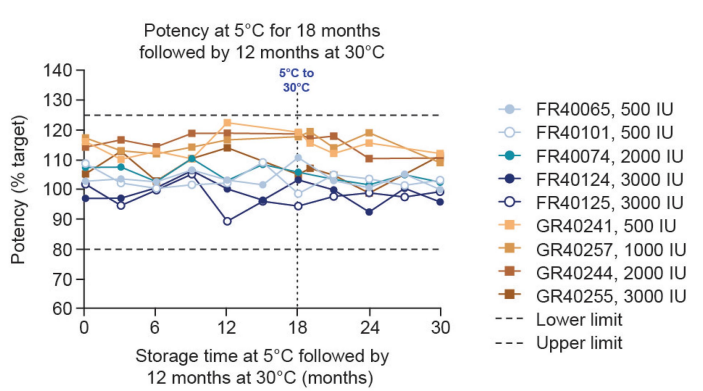

\section{G}

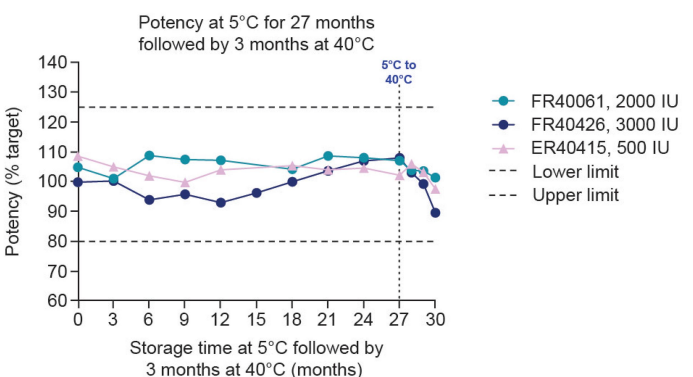

\section{H}

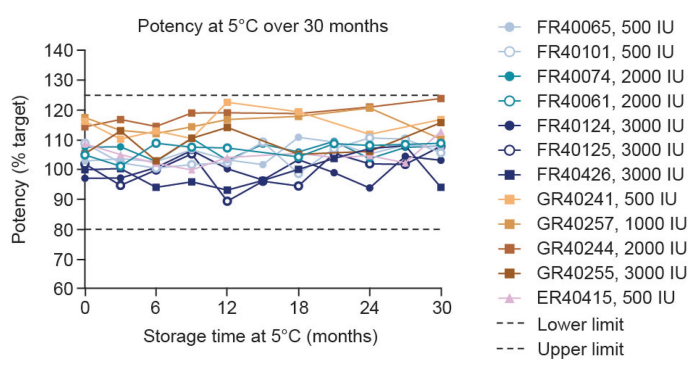

D

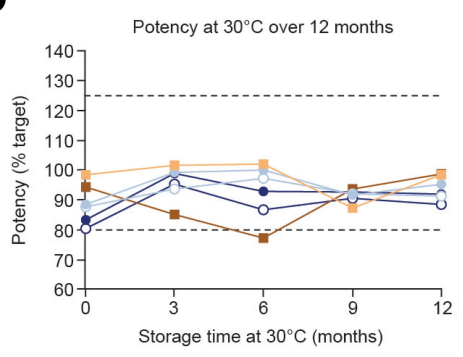

I

- AR40088, $250 \mathrm{IU}$ AR40093, 250 IU

- AR40094, $3000 \mathrm{IU}$

-O- AR40095, $3000 \mathrm{II}$

-YR40248, 250 IU

- YR40202, $3000 \mathrm{IU}$

--- Lower limit

--- Upper limit

E

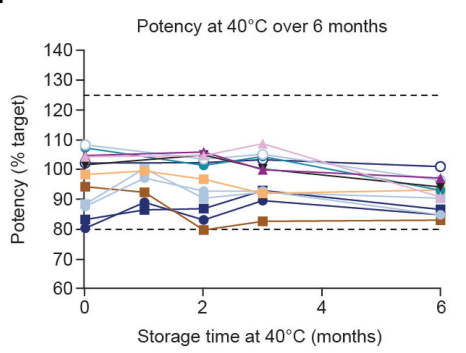

- FR40448, 250 IU

- FR40444, 2000 IU

- AR40093, 250 IU

AR40412, $250 \mathrm{IU}$

- AR40088, $250 \mathrm{IU}$

- AR40420, $2000 \mathrm{II}$

- AR40095, 3000 IU

-O AR40417, $3000 \mathrm{IU}$

- AR40094, $3000 \mathrm{IV}$

7. YR40248, $250 \mathrm{IU}$

- YR40202, $3000 \mathrm{IU}$

* GR40155, $3000 \mathrm{IU}$

-.- Lower limit

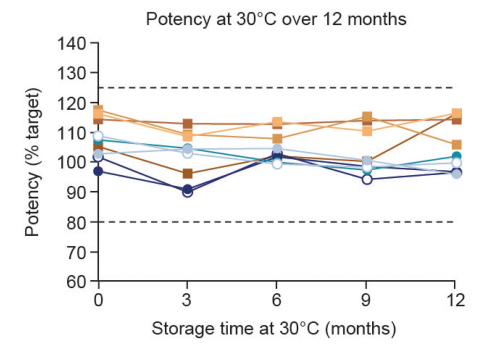

J

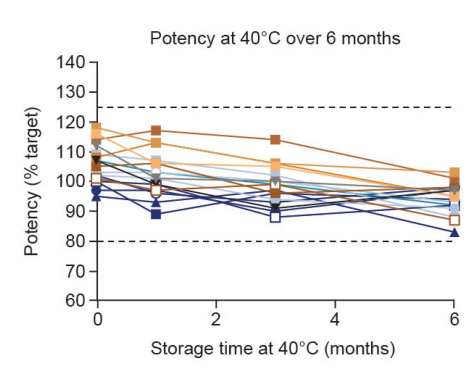

2- FR40065, $500 \mathrm{IU}$ FR40101, 500 IU

- FR40074, 2000 IU

- FR40124, 3000 IU

-OFR40125, $3000 \mathrm{IU}$

- GR40241, $500 \mathrm{IU}$

- GR40257, $1000 \mathrm{IU}$

- GR40244, 2000 IU

- GR40255, 3000 IU

--- Lower limit

-- Upper limit

- FR40250, 500 IU FR40065, $500 \mathrm{IU}$

-FR40074, 2000 IU

- FR40074, 2000 IU

- FR40124, 3000 IU

- FR40426,3000 IU

FR40426, 3000 IU

FR40277, $3000 \mathrm{IU}$

GR40241, 500 IU

GR40241, 500 IU

GR40257, 1000 IU

GR40244, 2000 IU

GR40255, 3000 IU

- GR40114, 3000 IU

* HR40835, $2000 \mathrm{IU}$

- Lower limit

-- Upper limit

Figure 4 Potency of turoctocog alfa dry powder samples when stored at $5^{\circ} \mathrm{C}$ for 21 months followed by storage at $30^{\circ} \mathrm{C}$ for 9 months $(\mathbf{A}), 5^{\circ} \mathrm{C}$ for 27 months followed by storage at $40^{\circ} \mathrm{C}$ for 3 months $(\mathbf{B}), 5^{\circ} \mathrm{C}$ for 30 months $(\mathbf{C}), 30^{\circ} \mathrm{C}$ for 12 months (D), and $40^{\circ} \mathrm{C}$ for 6 months $(\mathbf{E})$. Potency of turoctocog alfa pegol dry powder samples when stored at $5^{\circ} \mathrm{C}$ for 18 months followed by storage at $30^{\circ} \mathrm{C}$ for 12 months $(\mathbf{F}), 5^{\circ} \mathrm{C}$ for 27 months followed by storage at $40^{\circ} \mathrm{C}$ for 3 months $(\mathbf{G}), 5^{\circ} \mathrm{C}$ for 30 months $(\mathbf{H}), 30^{\circ}$

$\mathrm{C}$ for 12 months $(\mathbf{I})$, and $40^{\circ} \mathrm{C}$ for 6 months $(\mathrm{J})$. Upper and lower shelf-life limits for both products are shown by the horizontal dotted lines.

Abbreviation: IU, international units. 


\section{NovoEight}

A

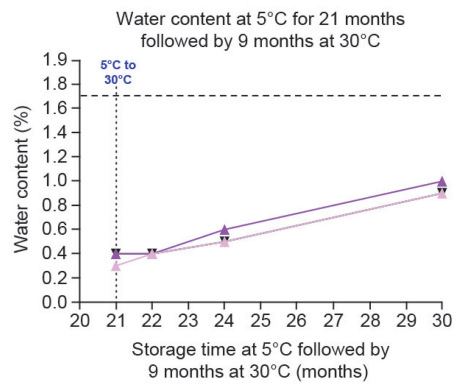

B

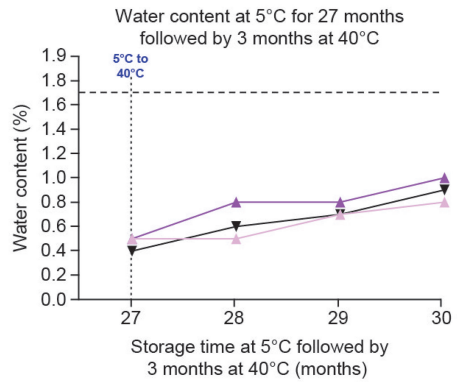

C

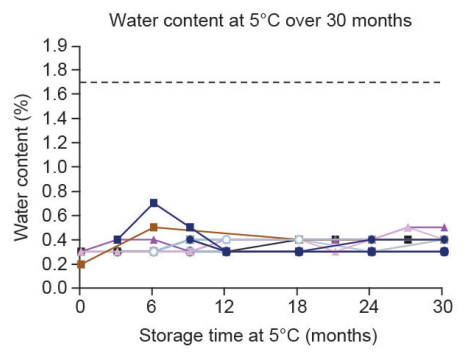

D

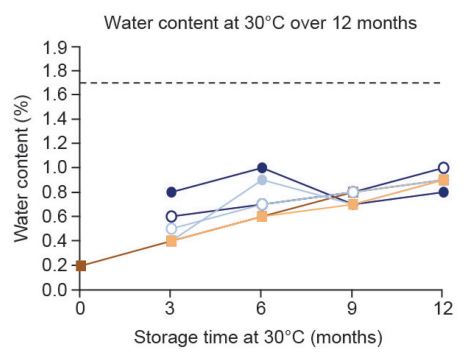

E

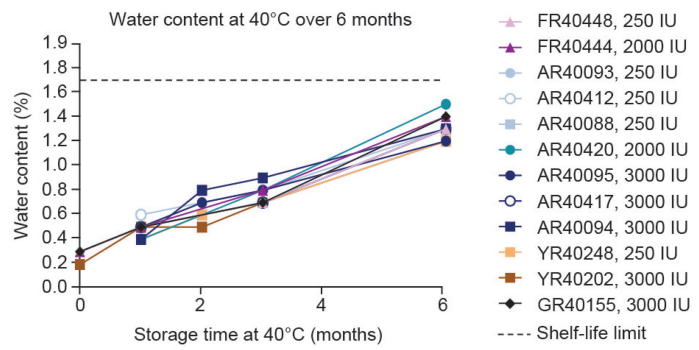

- GR40155, 3000 IU

- YR40202, $3000 \mathrm{IU}$

\section{Esperoct}

F

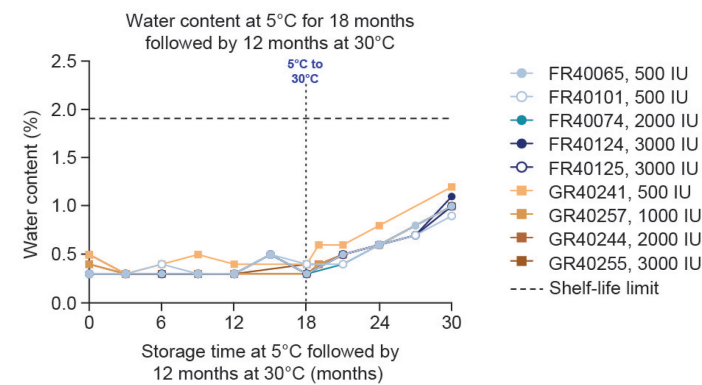

G

4- FR40448, $250 \mathrm{IU}$

- FR40444, $2000 \mathrm{IU}$

- GR40155, 3000 IU

-... Shelf-life limit

- FR40448, 250 IU

- FR40444, 2000 IV

AR40088, 250 IU

AR40093, 250 IU

- AR40412, 250 IU

- AR40420, 2000 IU

- AR40095, 3000 IU

- AR40094, $3000 \mathrm{IU}$

-O- AR40417, $3000 \mathrm{IU}$

-YR40248, $250 \mathrm{IU}$

- YR40202, $3000 \mathrm{IU}$

- Shelf-life limit

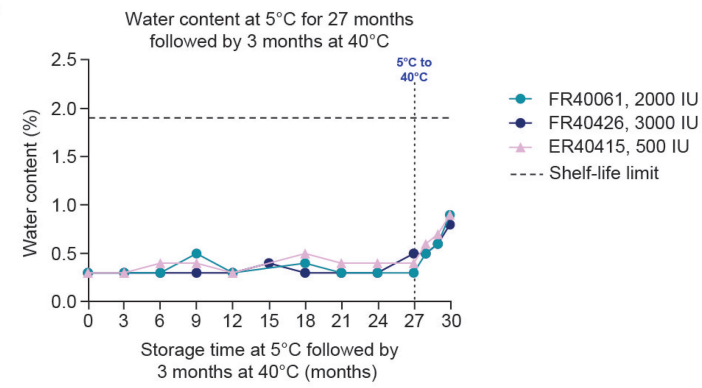

H

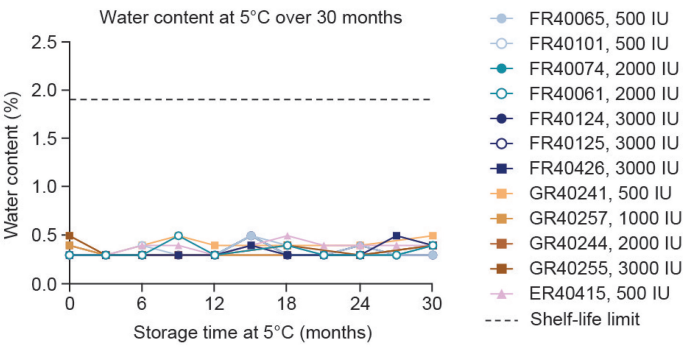

- AR40088, $250 \mathrm{IU}$ AR40093, 250 IU

- AR40094, $3000 \mathrm{IU}$

-O- AR40095, $3000 \mathrm{IU}$

- YR40248, 250 IU

-..-. Shelf-life limit

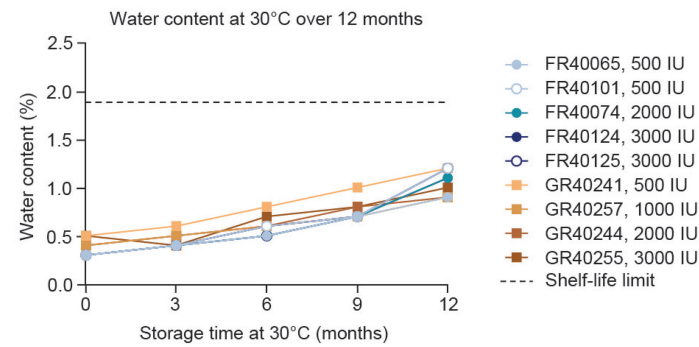

J

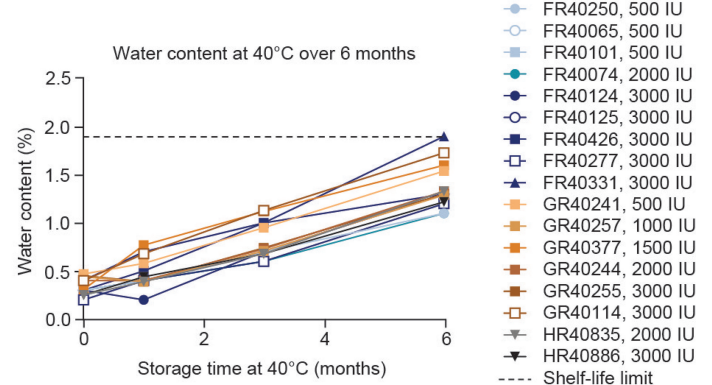

Figure 5 Water content of turoctocog alfa dry powder samples when stored at $5^{\circ} \mathrm{C}$ for 21 months followed by storage at $30^{\circ} \mathrm{C}$ for 9 months $(\mathbf{A}), 5^{\circ} \mathrm{C}$ for 27 months followed by storage at $40^{\circ} \mathrm{C}$ for 3 months (B), $5^{\circ} \mathrm{C}$ for 30 months (C), $30^{\circ} \mathrm{C}$ for 12 months (D), and $40^{\circ} \mathrm{C}$ for 6 months (E). Water content of turoctocog alfa pegol dry powder samples when stored at $5^{\circ} \mathrm{C}$ for 18 months followed by storage at $30^{\circ} \mathrm{C}$ for 12 months (F), $5^{\circ} \mathrm{C}$ for 27 months followed by storage at $40^{\circ} \mathrm{C}$ for 3 months $(\mathbf{G}), 5^{\circ} \mathrm{C}$ for 30 months $(\mathbf{H}), 30^{\circ} \mathrm{C}$ for 12 months $(\mathbf{I})$, and $40^{\circ} \mathrm{C}$ for 6 months $(\mathrm{J})$. Shelf-life limits for both products are shown by the horizontal dotted lines.

Abbreviation: IU, international units. 


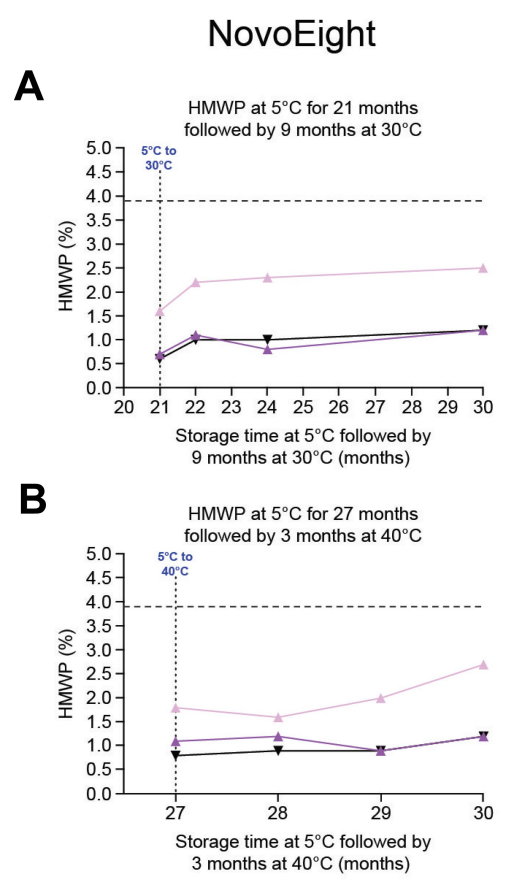

C

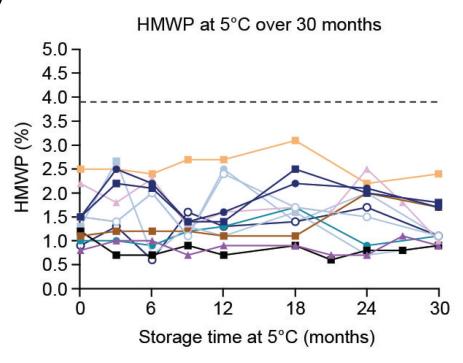

D

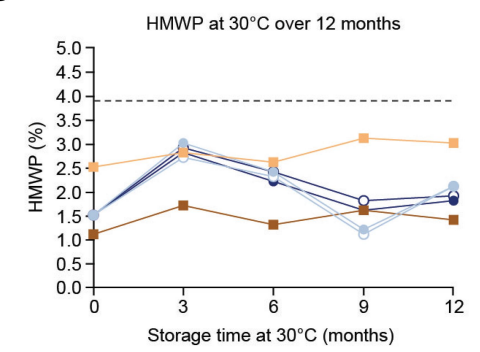

E

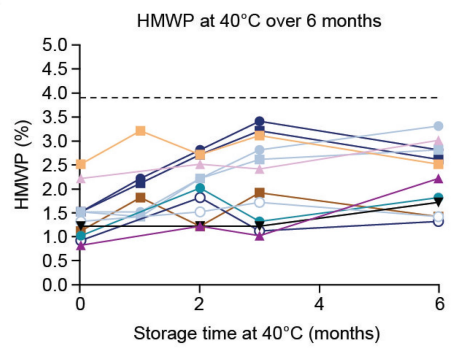

4- FR40448, 250 IU \# FR40444, $2000 \mathrm{IU}$ - -.. Shelf-life limit

- FR40448, 250 IU

\# FR40444, $2000 \mathrm{IU}$

* GR40155, $3000 \mathrm{IU}$

-..-. Shelf-life limit
4. FR40448, $250 \mathrm{IU}$

- FR40444, $2000 \mathrm{IU}$

- AR40088, 250 IU

AR40093, 250 IU

AR40093, $250 \mathrm{IU}$

- AR40420, $2000 \mathrm{II}$

- AR40095, $3000 \mathrm{IU}$

- AR40094, $3000 \mathrm{IV}$

-O- AR40417, $3000 \mathrm{IV}$

--YR40248, $250 \mathrm{IU}$

- YR40202, $3000 \mathrm{IU}$

- GR40155, $3000 \mathrm{IU}$

- Shelf-life limit -a- AR40088, 250 IU AR40093, $250 \mathrm{IU}$ - AR40094, $3000 \mathrm{IU}$ -O-AR40095, 3000 IU - YR40248, $250 \mathrm{IU}$ - YR40202, $3000 \mathrm{IU}$ -..-. Shelf-life limit
H

F

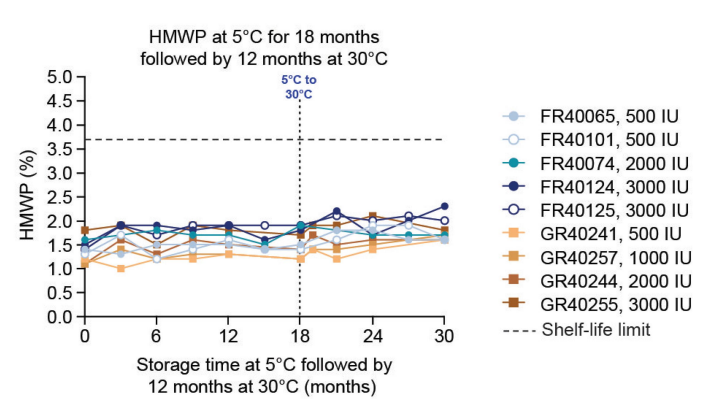

G

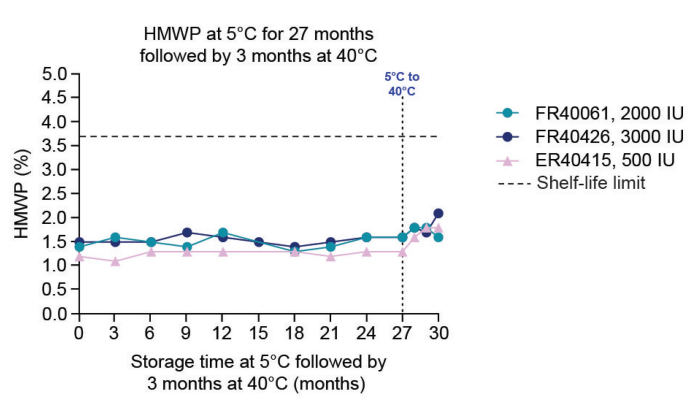

2. FR40065, $500 \mathrm{IU}$ FR40101, 500 IU

- FR40074, $2000 \mathrm{IU}$

- F- FR40061, 2000 IU

- FR40124, 3000 IU

-o- FR40125, 3000 IU

- FR40426, 3000 IU

- GR40241, 500 IU

- GR40257, $1000 \mathrm{IU}$

- GR40244, $2000 \mathrm{IU}$

- GR40255, $3000 \mathrm{IU}$

- ER40415, 500 IU

-.- Shelf-life limit

I

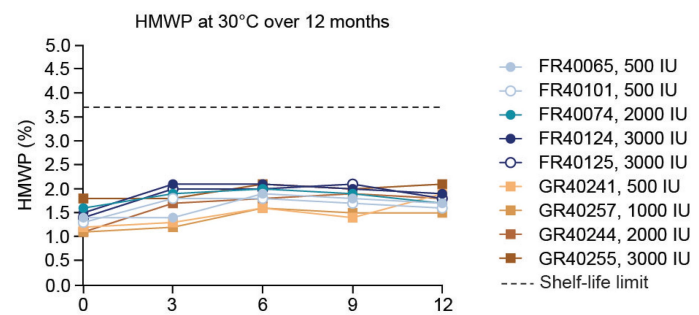

- FR40448, 250 IU

+ FR40444, $2000 \mathrm{IU}$

- AR40093, 250 IU

- AR40412, $250 \mathrm{IU}$

- AR40088, $250 \mathrm{IU}$

- AR40420, $2000 \mathrm{IU}$

- AR40095, $3000 \mathrm{IU}$

-O AR40417, $3000 \mathrm{II}$

- AR40094, 3000 IU

- YR40248, 250 IU

- YR40202, $3000 \mathrm{IU}$

- GR40155, $3000 \mathrm{IU}$

-.-. Shelf-life limit

J

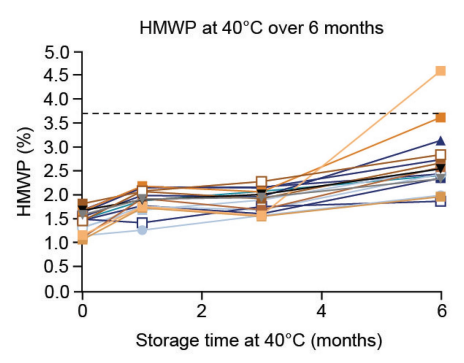

- FR40250, $500 \mathrm{IU}$ FR40101, 500 IU - FR40074, $2000 \mathrm{IU}$ - FR40124, 3000 IU - FR40125, 3000 II - FR40426, $3000 \mathrm{IU}$ 27. FR40277 $3000 \mathrm{IU}$ - FR40331,3000 IU GR40241, 500 IU GR40257, 1000 IU - GR40377, 1500 IU - GR40244, 2000 IU - GR40255, 3000 IU - GR40114, $3000 \mathrm{IU}$ * HR40835, 2000 IU * HR40886, 3000 IU -..- Shelf-life limit

Figure $6 \mathrm{HMWP}$ of turoctocog alfa dry powder samples when stored at $5^{\circ} \mathrm{C}$ for 21 months followed by storage at $30^{\circ} \mathrm{C}$ for 9 months $(\mathbf{A}), 5^{\circ} \mathrm{C}$ for 27 months followed by storage at $40^{\circ} \mathrm{C}$ for 3 months (B), $5^{\circ} \mathrm{C}$ for 30 months (C), $30^{\circ} \mathrm{C}$ for 12 months (D), and $40^{\circ} \mathrm{C}$ for 6 months (E). HMWP of turoctocog alfa pegol dry powder samples when stored at $5^{\circ} \mathrm{C}$ for 18 months followed by storage at $30^{\circ} \mathrm{C}$ for 12 months $(\mathbf{F}), 5^{\circ} \mathrm{C}$ for 27 months followed by storage at $40^{\circ} \mathrm{C}$ for 3 months $(\mathbf{G}), 5^{\circ} \mathrm{C}$ for 30 months $(\mathbf{H}), 30^{\circ}$ $\mathrm{C}$ for 12 months (I), and $40^{\circ} \mathrm{C}$ for 6 months (J). Shelf-life limits for both products are shown by the horizontal dotted lines.

Abbreviations: HMWP, high molecular weight protein; IU, international units. 
75\% RH for 12 months (Figure 6D and I) and, for all but one batch (turoctocog alfa pegol at $500 \mathrm{IU}$ ), $<4 \%$ after storage at $40^{\circ} \mathrm{C} / 75 \% \mathrm{RH}$ for 6 months (Figure $6 \mathrm{E}$ and $\mathrm{J}$ ).

It was noted that there was some variability in HMWP for both turoctocog alfa and turoctocog alfa pegol due to analytical issues encountered at low concentrations. HMWP is oligomeric forms of the monomer of turoctocog alfa and turoctocog alfa pegol, eluting ahead of the monomer in SE-HPLC.

\section{Discussion}

The ICH guidelines state that well-defined stability studies should be developed to confirm product stability during the intended storage period. ${ }^{30}$ We assessed key stability parameters for both turoctocog alfa and turoctocog alfa pegol; these parameters are susceptible to change during storage and/or could potentially influence product quality, namely oxidized forms, potency, water content, and HMWP. There were no major increases in oxidized forms or HMWP and no impairment in potency or water content for either product; most results were within each product's range. Although FVIII activity (potency) and protein aggregates (HMWP) were largely unaffected, a small increase in oxidized forms was observed after storage at $30^{\circ} \mathrm{C} / 75 \% \mathrm{RH}$ for 12 months and after storage at $40^{\circ} \mathrm{C} / 75 \% \mathrm{RH}$ for 6 months. However, the changes in oxidized forms for both turoctocog alfa and turoctocog alfa pegol at high temperatures up to $40^{\circ} \mathrm{C}$ did not affect the quality of either product. Oxidized forms are inactive forms of rFVIII and a correlation between potency and oxidized forms can be expected. ${ }^{33}$ For example, oxidation of FVIII has been reported to correlate with the oxidation of free Cys and disulfide bonds, leading to structural change and loss of potency. ${ }^{33}$

Interestingly, turoctocog alfa can be subjected to variable storage conditions, including cycling between $5^{\circ} \mathrm{C}$ and $\leq 40^{\circ} \mathrm{C}$, and subsequent storage for 3 months up to $40^{\circ} \mathrm{C}$, without loss of stability. ${ }^{37}$ As of yet, no temperature cycling data are available for turoctocog alfa pegol. However, among commercially available EHL-rFVIII products, turoctocog alfa pegol is the only one that has shown stability at $40^{\circ} \mathrm{C}^{13}$ Thus, the current stability data should reassure patients who are receiving turoctocog alfa and considering switching to turoctocog alfa pegol. Furthermore, as the current study shows that both products can be safely stored at temperatures up to $40^{\circ} \mathrm{C} / 75 \% \mathrm{RH}$ for 3 months without compromising product potency, patients can also be reassured that the dose on the vial label is unaffected - and therefore dose adjustments are not required-when either product is stored outside the refrigerator for several months. Patients should note the date when turoctocog alfa and turoctocog alfa pegol are taken out of the fridge so they can ensure that the duration of room-temperature storage does not exceed 3 months.

Home treatment of hemophilia is necessary and recommended: the World Federation of Hemophilia recommends acute bleeds should be treated as quickly as possible, preferably within $2 \mathrm{hrs}^{2}$ Patients/caregivers of those with hemophilia A have reported preferences for FVIII products that can be stored at higher temperatures for long periods of time, both overall and when travelling. ${ }^{15,16}$ However, in one small study, only $13 \%$ of patients and caregivers were aware of their product's storage conditions, ${ }^{38}$ while another study showed that $80 \%$ of patients/caregivers who stored FVIII in the refrigerator did not know that their product may be safely stored at room temperature for a limited number of months. ${ }^{15}$ Therefore, it is important for patients to know if there is a meaningful, clinical difference between an FVIII product kept outside of the fridge for $48 \mathrm{hrs}$ (for example) compared with one kept in the fridge for 3 months. Our study shows that both turoctocog alfa and turoctocog alfa pegol remained stable when stored at a relatively high ambient room temperature and humidity $\left(40^{\circ} \mathrm{C} / 75 \% \mathrm{RH}\right)$ for up to 3 months following an extended storage period at $5^{\circ} \mathrm{C}$. Two other rFVIII products (Advate ${ }^{\circledR}$ and Recombinate ${ }^{\circledR}$ [Takeda, Lexington, MA]) are thermostable at $30^{\circ} \mathrm{C}-40^{\circ} \mathrm{C} ;{ }^{39,40}$ however, at the time of writing and to the best of our knowledge, turoctocog alfa and turoctocog alfa pegol are the only FVIII and EHL FVIII products, respectively, licensed for storage at temperatures up to $40^{\circ} \mathrm{C}$.

These data are of clinical importance, as they demonstrate that the stability of both products may offer flexibility and greater convenience in product storage and daily use. Benefits of increased storage flexibility and portability include the ability to keep more FVIII product at home, the ability to travel more easily, reduced daily disruption ${ }^{15,16}$ and, potentially, lead a more active lifestyle. The resulting improvement in convenience may also contribute to better treatment outcomes and quality of life by facilitating early treatment of bleeds ${ }^{15,17}$ and improving adherence to the recommended prophylaxis schedules. These benefits would be particularly relevant for patients who live in, or who travel to, countries where daytime temperatures are consistently or transiently above $30^{\circ} \mathrm{C}$, and even up to $40^{\circ} \mathrm{C}$. It is therefore crucial for hemophilia care providers to clearly explain to patients and/or 
caregivers that FVIII products such as turoctocog alfa and turoctocog alfa pegol can be kept at room temperature for extended periods (assuming no higher than $40^{\circ} \mathrm{C}$ ) while remaining clinically effective to use.

\section{Conclusion}

Turoctocog alfa and turoctocog alfa pegol offer stability at $40^{\circ} \mathrm{C} / 75 \% \mathrm{RH}$ for up to 3 months without jeopardizing the quality of either product. These stability characteristics may be beneficial to patients by allowing flexibility in product storage and daily use.

\section{Data Sharing Statement}

Novo Nordisk's policy on data sharing may be found at https://www.novonordisk-trials.com/how-access-clinicaltrial-datasets.

\section{Acknowledgments}

The authors wish to thank Patrycia Wojtyniak Dahl and Sigrun Debes Johansen for design and execution of the study. Julie Smith and Jo Fetterman (Parexel) provided drafts and editorial assistance to the authors during the preparation of this manuscript, supported by funding from Novo Nordisk A/S.

\section{Author Contributions}

All authors made a significant contribution to the work reported, whether that is in the conception, study design, execution, acquisition of data, analysis and interpretation, or in all these areas; took part in drafting, revising or critically reviewing the article; gave final approval of the version to be published; have agreed on the journal to which the article has been submitted; and agree to be accountable for all aspects of the work.

\section{Funding}

This work was supported by funding from Novo Nordisk $\mathrm{A} / \mathrm{S}$.

\section{Disclosure}

$\mathrm{MN}$ has acted as a consultant for Amgen, Bayer, BIOFVIIIx and Novo Nordisk, and received speaker fees from Baxalta, Bayer, CSL Behring, Kedrion, Novo Nordisk, Sobi, Takeda, and Octapharma; AAO and AMN are employees of Novo Nordisk A/S. The authors report no other conflicts of interest in this work.

\section{References}

1. Pipe S. Antihemophilic factor (recombinant) plasma/albumin-free method for the management and prevention of bleeding episodes in patients with hemophilia A. Biologics. 2009;3:117-125. doi:10.2147/ btt.2009.2872

2. Srivastava A, Brewer A, Mauser-Bunschoten E, et al. Guidelines for the management of hemophilia. Haemophilia. 2013;19(1):e1-47.

3. Mancuso ME, Santagostino E. Outcome of clinical trials with new extended half-life FVIII/IX concentrates. J Clin Med. 2017;6(4):39. doi: $10.3390 /$ jcm6040039

4. Advate [prescribing information]. Baxter Healthcare Corporation; 2011. Available from: https://www.fda.gov/downloads/ BloodBloodProducts/ucm059095.pdf. Accessed September 18, 2018.

5. Kogenate [summary of product characteristics]. Bayer HealthCare Manufacturing SRL; 2018. Available from: http://www.ema.europa. eu/ema/index.jsp?curl=pages/medicines/human/medicines/000275/ human_med_000879.jsp\&mid=WC0b01ac058001d124. Accessed September 28, 2018.

6. NUWIQ [prescribing information]. Octapharma AB; 2015. Available from: https://www.fda.gov/downloads/BiologicsBloodVaccines/ BloodBloodProducts/ApprovedProducts/LicensedProductsBLAs/ FractionatedPlasmaProducts/UCM461328.pdf. Accessed September 28, 2018.

7. NovoEight ${ }^{\circledR}$ [summary of product characteristics]. Novo Nordisk A/ S; 2018. Available from: http://www.ema.europa.eu/docs/en_GB/ document_library/EPAR_-_Product_Information/human/002719/ WC500157553.pdf. Accessed August 23, 2018.

8. NovoEight ${ }^{\circledR}$. [Highlights of prescribing information]. Available from: https://www.novo-pi.com/novoeight.pdf. Accessed August 10, 2018.

9. Jivi [summary of product characteristics]. Bayer AG; 2019. Available from: https://www.ema.europa.eu/en/documents/product-information /jivi-epar-product-information_en.pdf. Accessed November 14, 2019.

10. ELOCTATE [summary of product characteristics]. Swedish Orphan Biovitrum AB; 2019. Available from: https://www.ema.europa.eu/en/ documents/product-information/elocta-epar-product-information_en. pdf. Accessed November 14, 2019.

11. ADYNOVATE [package insert]. Baxalta US Inc; 2019. Available from: https://www.fda.gov/files/vaccines, $\% 20$ blood $\% 20 \& \% 20$ biolo gics/published/Package-Insert-ADYNOVATE.pdf. Accessed November 14, 2019.

12. AFSTYLA [summary of product characteristics]. CSL Behring GmBH; 2019. Available from: https://www.ema.europa.eu/en/docu ments/product-information/afstyla-epar-product-information_en.pdf. Accessed November 14, 2019.

13. ESPEROCT. [Summary of product characteristics]. Available from: https://www.ema.europa.eu/en/documents/product-information/esper oct-epar-product-information_en.pdf. Accessed 14 November 2019.

14. ESPEROCT [package insert]. Novo Nordisk A/S; 2019. Available from: https://www.fda.gov/media/120351/download. Accessed November 14, 2019.

15. Tischer B, Marino R, Napolitano M. Patient preferences in the treatment of hemophilia A: impact of storage conditions on product choice. Patient Prefer Adherence. 2018;12:431-441. doi:10.2147/ PPA.S151812

16. DiBenedetti D, Coles T, Sharma T, Pericleous L, Kulkarni R. Assessing patients' and caregivers' perspectives on stability of factor VIII products for haemophilia A: a web-based study in the United States and Canada. Haemophilia. 2014;20(4):e296-e303. doi:10.1111/hae.12459

17. Saxena K. Barriers and perceived limitations to early treatment of hemophilia. J Blood Med. 2013;4:49-56. doi:10.2147/JBM.S43734

18. Shannon E, Daffy J, Jones H, Paulson A, Vicik SM. Etanercept (Enbrel) alternative storage at ambient temperature. Clin Pharmacol. 2017;9:87-99. doi:10.2147/CPAA.S131832 
19. World Health Organization. WHO Expert Committee on Specifications for Pharmaceutical Preparations. WHO Technical Report Series 953; forty-third report; 2009. Available from: http:// apps.who.int/iris/bitstream/handle/10665/44553/WHO_TRS_953_ eng.pdf?sequence=1. Accessed November 1, 2018.

20. Kulkarni R, Karim F, Glamocanin S, et al. Results from a large multinational clinical trial (guardian3) using prophylactic treatment with turoctocog alfa in paediatric patients with severe haemophilia A: safety, efficacy and pharmacokinetics. Haemophilia. 2013;19 (5):698-705. doi:10.1111/hae.12165

21. Santagostino E, Lentz SR, Misgav M, et al. Safety and efficacy of turoctocog alfa (NovoEight ${ }^{\circledR}$ ) during surgery in patients with haemophilia A: results from the multinational guardian clinical trials. Haemophilia. 2015;21(1):34-40. doi:10.1111/hae.12518

22. Lentz S, Misgav M, Ozelo M, et al. Results from a large multinational clinical trial (guardian1) using prophylactic treatment with turoctocog alfa in adolescent and adult patients with severe haemophilia A: safety and efficacy. Haemophilia. 2013;19(5):691-697. doi:10.1111/hae.12159

23. Curry N, Albayrak C, Escobar M, et al. Once-weekly prophylaxis with glycoPEGylated recombinant factor VIII (N8-GP) in severe haemophilia A: safety and efficacy results from pathfinder 2 (randomized Phase III trial). Haemophilia. 2019;25(3):373-381. doi: $10.1111 /$ hae. 13712

24. Giangrande P, Andreeva T, Chowdary P, et al. Clinical evaluation of glycoPEGylated recombinant FVIII: efficacy and safety in severe haemophilia A. Thromb Haemost. 2017;117(2):252-261. doi:10.1160/TH16-06-0444

25. Hampton K, Chowdary P, Dunkley S, et al. First report on the safety and efficacy of an extended half-life glycoPEGylated recombinant FVIII for major surgery in severe haemophilia A. Haemophilia. 2017;23(5):689-696. doi:10.1111/hae.13246

26. Meunier S, Alamelu J, Ehrenforth S, et al. Safety and efficacy of a glycoPEGylated rFVIII (turoctocog alpha pegol, N8-GP) in paediatric patients with severe haemophilia A. Thromb Haemost. 2017;117 (9):1705-1713. doi:10.1160/TH17-03-0166

27. Stennicke HR, Kjalke M, Karpf DM, et al. A novel B-domain O-glycoPEGylated FVIII (N8-GP) demonstrates full efficacy and prolonged effect in hemophilic mice models. Blood. 2013;121 (11):2108-2116. doi:10.1182/blood-2012-01-407494

28. Ellgaard TW, Bindslev L, Kamstrup S. Evaluation of the virus clearance capacity and robustness of the manufacturing process for the recombinant factor VIII protein, turoctocog alfa. Protein Expr Purif. 2017;129:94-100. doi:10.1016/j.pep.2016.09.002
29. Agerso H, Stennicke HR, Pelzer H, et al. Pharmacokinetics and pharmacodynamics of turoctocog alfa and N8-GP in haemophilia A dogs. Haemophilia. 2012;18(6):941-947. doi:10.1111/j.13652516.2012.02896.x

30. International Conference on Harmonisation of Technical Requirements for Registration of Pharmaceuticals for Human Use. ICH Harmonised Tripartite Guideline: quality of Biotechnological Products: stability Testing of Biotechnological/Biological Products Q5C. Current Step 5 version. Available from: https://www.ema. europa.eu/en/documents/scientific-guideline/ich-topic-q-5-c-qualitybiotechnological-products-stability-testing-biotechnological/biologi cal-products_en.pdf. Accessed May 19, 2020.

31. European Pharmacopoeia. 10th Edition. Available from: https://www. edqm.eu/en/european-pharmacopoeia-ph-eur-10th-edition. Accessed May 19, 2020.

32. Eldin A, Shalaby A. Comparison of FT-NIR transmission and HPLC to assay montelukast in its pharmaceutical tablets. Am J Analytical Chem. 2011;2(8):885-891. doi:10.4236/ajac.2011.28102.

33. Wang W, Wang YJ, Kelner DN. Coagulation factor VIII: structure and stability. Int $J$ Pharm. 2003;259(1-2):1-15. doi:10.1016/S03785173(03)00227-8

34. Butenas S, Parhami-Seren B, Gissel MT, Gomperts ED, Fass DN, Mann KG. Potency and mass of factor VIII in FVIII products. Haemophilia. 2009;15(1):63-72. doi:10.1111/j.1365-2516.2008.01826.x

35. Yoshioka S, Aso Y. Correlations between molecular mobility and chemical stability during storage of amorphous pharmaceuticals. J Pharm Sci. 2007;96(5):960-981. doi:10.1002/jps.20926

36. Rosenberg AS. Effects of protein aggregates: an immunologic perspective. AAPS J. 2006;8(3):E501-507. doi:10.1208/aapsj080359

37. Napolitano M, Nohr AM. The effect of fluctuating temperature on the stability of turoctocog alfa for hemophilia A. Drugs R D. 2019;19 (4):381-390. doi:10.1007/s40268-019-00290-3

38. Novais T, Duclos A, Varin R, Lopez I, Chamouard V. Treatmentrelated knowledge and skills of patients with haemophilia and their informal caregivers. Int $J$ Clin Pharm. 2016;38(1):61-69. doi:10.1007/s11096-015-0207-z

39. Parti R, Ardosa J, Yang L, Mankarious M. In vitro stability of recombinant human factor VIII (Recombinate). Haemophilia. 2000;6(5):513-522. doi:10.1046/j.1365-2516.2000.00410.x

40. Parti R, Schoppmann A, Lee H, Yang L. Stability of lyophilized and reconstituted plasma/albumin-free recombinant human factor VIII (ADVATE rAHF-PFM). Haemophilia. 2005;11(5):492-496. doi:10.1111/j.1365-2516.2005.01128.x
Journal of Blood Medicine

\section{Publish your work in this journal}

The Journal of Blood Medicine is an international, peer-reviewed, open access, online journal publishing laboratory, experimental and clinical aspects of all aspect pertaining to blood based medicine including but not limited to: Transfusion Medicine; Blood collection, Donor issues, Transmittable diseases, and Blood banking logistics; Immunohematology; Artificial and alternative blood based therapeutics; Hematology; Biotechnology/nanotechnology of blood related medicine; Legal aspects of blood medicine; Historical perspectives. The manuscript management system is completely online and includes a very quick and fair peer-review system. Visit http://www.dovepress.com/testimonials.php to read real quotes from published authors. 